\title{
Graphic-Stylistic Expressivity in Media Discourse
}

\author{
Marina Yu. Ryabova* \\ Kemerovo State University, 650000, 6, ul. Krasnaya, Kemerovo, Russia
}

\begin{abstract}
The article deals with the analysis of graphic-stylistic means of the language, such as punctuation, functioning in modern English based on the language material of literary and media texts (online site of The Guardian). The aim of the paper is to reveal some actual functional characteristics of punctuation marks compared with their traditional syntactic and stylistic usage. The linguistic analysis is conducted within the methodology of semantic and syntactic interpretation and description. The following new functional usage of punctuation marks is described: the playing (ludic) function (creating an ironic, comic or parody effect in communication) and the expressive function emphasizing the semantics of an element in a communicative context. The importance of the undertaken analysis is to show the necessity of studying the English punctuation functions from the point of view of modern theory of communication and media linguistics as well as with an empirical educational purpose of teaching the English grammar.
\end{abstract}

\section{Introduction}

It is not a secret that punctuation rules in the English language are complex and intricate. Besides, it is not an easy task to find a compiled theory of English punctuation in grammar books; punctuation rules are formulated in special books on style, instructions for authors or editors. Meanwhile, punctuation often influences radically the total meaning of the text, e.g.:

A woman, without her man, is nothing;

A woman: without her, man is nothing.

In 2004 Lynne Truss published a book, entitled "Eats, Shoots \& Leaves", which is devoted to punctuation in the modern English language, and where the problem of punctuation is discussed with humor, irony and deep understanding of the grammatical nature of the question. In the dedication to the book she wrote, «To the memory of the striking Bolshevik printers of St Petersburg who, in 1905, demanded to be paid the same rate for punctuation marks as for letters, and thereby directly precipitated the first Russian Revolution» [1, VI]. Curious enough that a reference to Russian punctuation is rather symbolic, because the punctuation rules in Russian are equally intricate and complex as in English. This fact was mentioned by authoritative Russian scholar L. Scherba, who said that Russian punctuation, as well as Russian spelling, developed rather spontaneously, and nowadays it is absolutely not clear what it should express - the ideas proper or the means and ways of their presentation. The complexity of the question is aggravated by the fact that different expressive means often contradict to each other in practice [2]. Thus, punctuation both in English or in
Russian is a rather complex question, and the result of arranging punctuation marks can be dramatic for the total meaning of the utterance, and sometimes it can radically change the meaning.

For the title of the book L. Truss chose a famous punctuation-fan joke about a panda, who walks into a café, orders a sandwich, eats it, then draws a gun and proceeds to fire it at the other patrons. "Why?" asks the confused, surviving waiter amidst the carnage, as the panda makes towards the exit. The panda produces a badly punctuated wildlife manual and tosses it over his shoulder. "Well, I'm a panda," he says. "Look it up." The waiter turns to the relevant entry in the manual and, sure enough, finds an explanation: "Panda. Large black-andwhite bear-like mammal, native to China.

Eats, shoots and leaves".

\section{Discussion: expressivity of graphic signs of the language}

Punctuation is a system of graphic non-alphabetic signs and rules, codifying the norms of written organization of a text. Punctuation signs together with graphics and spelling form the basic written means of a language; the main aim of punctuation is division and graphic organization of a written text. One of the best definition of punctuation is in the book by T. McCormack, who says that the purpose of punctuation is "to tango the reader into the pauses, continuities and connections that the spoken line would convey. Punctuation to the writer is like anatomy to the artist: he learns the rules so he can knowledgeably and controllédly depart from them as art requires. Punctuation is a means, and its end is: helping the reader to hear, to follow" [3]. 
Common functions of punctuation in Indo-European languages are as follows: the function of division, and the function of highlighting text elements or their groups. There are paired and single punctuation marks. Signs can serve to divide the text and / or sentence. The function of division of a sentence is actualized by such signs as: comma, semicolon, dash, colon, dots, brackets, quotation marks. The function of division of a text is conducted by such signs as: a period, a question mark, an exclamation point, dots, brackets, quotes. In IndoEuropean languages, the common functions of punctuation are: the organization of syntactic relations within constructions; the expression of semantic links within the utterance; an indication of the intonational contour of the utterance; the expression of rhythm and melody of speech; codification of communicative speech division; the expression of the emphatic function of an utterance.

As M.V. Divakova rightly noted, recognizing the multiplicity and diversity of the factors determining the choice and use of punctuation signs, it is possible to determine the functional significance of punctuation marks. "It is difficult to do this because the current system of rules is both rigid, strictly regulated, and mobile, open for variable use. It is generally accepted that the punctuation rules in modern Russian are mostly optional. This is the main property of punctuation, which makes it possible to give accuracy, expressiveness, and consistency to a written text. The influence of the context on the choice of a sign has long been noted by researchers. However, sometimes the choice of a single possible sign is dictated not by the semantics of the sentence, but only by the author's setting. In this aspect, the task is to clarify the distinction between optional punctuation marks and author's signs "[4, p. 2]. In English, the punctuation system is a complex and multifunctional area. According to the authoritative English researcher, the author of the encyclopedia "Language" D. Crystal, the punctuation system in English has two main functions: the function of the division of a written text and the function of indicating the rhythmic and intonational pattern of the text. He distinguishes two groups of signs: signs that separate, and signs that convey meaning. The group of features that separate includes the following signs: 1) space: separates words, identifies paragraphs; 2) period (full stop): identifies the end of the sentence, used to mark abbreviations, a sequence of periods indicates that the text is incomplete; 3) semi-colon: identifies the coordinate parts of a compound sentence, or separates complex points in a list; 4) colon: used mainly to show that what follows it is an implification or explanation of what precedes it; 5) comma: a wide range of uses, such as marking a sequence of grammatical units, or a unit used inside another; displays a great deal of personal variation (such as whether it should be used before and in such lists as apple, pears, and plums); 6) parentheses ( ) and brackets []: used as an alternative to commas to mark the inclusion of a grammatical unit in the middle or at the end of a sentence; 7) dash: used in pairs with the same function as parentheses or brackets; used singly to separate a comment or afterthought occurring at the end of a sentence or to express an incomplete utterence; in informal writing, often replaces other punctuation marks; 8) quotation marks (inverted commas): identify the beginning and end of an extract of speech, a title, a citation, the 'special' use of a word; 9) hyphen: marks two kinds of divisions within a word - to show that a word has been split in two because of the end of a line, and to relate the part of a phrase or compound word to each other (as in pickled-herring merchant - vs. pickled herring-merchant) [5, p. 207]. Punctuation signs that convey meaning are: 1) question mark: usually expresses a question, but occasionally found with other functions, such as marking silence or uncertainty (e.g. this is an interesting (?) point); 2) exclamation mark: shows varying degrees of exclamatory force (e.g. !!!); also some special uses (e.g. John (!) was there); 3) apostrophe: used to mark the genitive singular or plural, and grammatical contractions ( I'm, won't), in certain words (o'clock, fish'n'chips), subject to a great deal of usage variations (St Johns or St John's? Harrods or Harrod's?) [Ibid].

The punctuation marks listed above characterize the standard, normative use of a written speech. Today, under the influence of virtual electronic communication forms (sites, blogs, chats, instagram and other social networks, etc.), the norms of punctuation are increasingly violated, becoming freer and more mobile, which is reflected in the fact that some punctuation marks start to perform unusual functions, i.e. they are used in an unusual context, sometimes erroneously, sometimes performing other functions (for example, playing or ludic). So, some interesting examples of the unusual use of an apostrophe in the modern English language are cited by L. Truss, cf. .: Come inside for $C D$ 's, DVD's, VIDIO's and BOOK's [1, p.1], where the apostrophe marks the plural forms of nouns.

In another example, the misuse of the apostrophe leads to misunderstanding and distortion of information, since the article is not about a raging fan, but about a crowd of fans who organized riots, cf. .. FAN'S FURY AT STADIUM INQUIRY [Ibid: p. 2]. Researchers note that a deviation from the norms of punctuation can lead to a distortion of the meaning and, consequently, to misunderstanding.

However, sometimes a deviation of the normative use of punctuation is intentional and reflects a playing function of the language [7], designed to attract the attention of the reader or listener to the text. Typically, this use of punctuation is characteristic of an advertising discourse, in which unusual punctuation is intended to catch the reader's attention «relying entirely on a visual association of ideas»[7, p. 94]. This problem was analyzed in the study of Yu.V. Popova, who noted that at present it is possible to talk about the formation of a special direction in linguistics - graphic stylistics, designed to study graphic stylistic devices of the language, which have certain signs of language play on the basis of reference to written and oral discourses [8, p.112]. According to the author, a distinctive feature of graphic-stylistic devices is that their understanding is impossible without visual contemplation. "Graphic play as an expressive technique is a font, color, spatial, 
punctuational actualization (quotation marks, dashes, brackets, hyphens) of the component" [Ibidem, p. 112]. But the graphic play used in the message, as it were, is "layered" over the verbal component of the utterance, amplifying or weakening it. The playing effect can be achieved by using an apostrophe in the title, e.g. St'ile de Beaute, or a hyphen: Bar-B-Q (the name of the bar); dots: Jaguar. The art of performance. Grace ... space ... pace ....V. Z. Sannikov notes that sometimes authors deliberately violate the rules of punctuation as a method of parodying the stylistics of another author [9, p.58].

Thus, we know that, the stylistics of Russian poet Vladimir Mayakovsky is characterized by a broken line and an intricate punctuation, creating a special rhythm and space, $\mathrm{cf}$.:

\begin{tabular}{|l|l|}
\hline Тьл & You \\
Пришла- & You came - \\
деловито, & attracted \\
за рылом, & by my roar \\
за ростом, & and my height, \\
взглянув, & but looked closer \\
разглядела просто & and saw there, merely a \\
мальчика. & boy. \\
Взяла, & You \\
отобрала сердие & took my heart away, \\
и просто & like it was all right, \\
пошла играть- & and went on playing,- \\
как девочка мячиком. & just a girl with her toy. \\
& \\
\hline
\end{tabular}

As can be seen, the most typical stylistic device employed by the poet here is parcellation, actualized by means of commas and dashes. His style is easily parodied by another poet G. Kareisha:

\begin{tabular}{|c|l|}
\hline Во & Oh \\
! & $!$ \\
Маяковский & Mayakovsky \\
тебе & don't \\
не & you \\
икается & hiccup \\
$?$ & $?$ \\
У & You \\
тебя & have \\
два & two \\
слова & words \\
на & in \\
строчку, & a \\
а & line, \\
у & while \\
нас & we \\
уже & have \\
полагается & a \\
строчка & line \\
даже & even \\
на & for \\
точку. & a period. \\
& (translation) \\
\hline
\end{tabular}

\section{The analysis of syngraphemics in media discourse}

In its expressive function, punctuation can increase the emotional impact on the addressee, attract the reader's attention, emphasizing the unusualness of other language expressive means. This method of using the mechanisms of punctuation variation is known as the phenomenon of syngraphemics [10], and it involves the use of quotes, a hyphen, an exclamation mark or other punctuation marks in the title or in a word.

Very often, this method of an expressive use of punctuation marks is found in the headlines of media texts, especially on the pages of the British online edition of "The Guardian", e.g.: Brit(ish) review - what does it mean to be black and British now? [11]. In the title, the attention is drawn to the spelling of the word Brit(ish), in which the suffix is highlighted in parentheses, this unusual graphics allows the reader to think about the ambiguous reading of the given word, in which two semantic meanings actualize: British as a nationality and citizenship, and the meaning associated with the semantics of the suffix -ish (something like that, roughly, approximately; the meaning of the word can be interpreted as "something similar to Britishness"). Thus, the author of the article draws the reader's attention to the problem of non-white population of Britain who, being citizens of this country, feel their foreignness.

The expressive, emphasizing function of punctuation is observed not only in the headlines of media texts, but also within the content of the texts, as practically all punctuation marks are characterized by the ability to emphasize additional meanings. See another example from "The Guardian" [12]: the title of the article reads: Ignore the naysayers: the 2017 election youthquake was not a myth. In this case, the opposition of theses in the composition of the first and second subordinate clauses is emphasized with the help of the colon, which adds more emotional expressiveness to the content of the sentence. Below in the text of the article, expressive punctuation potentials help to make the necessary semantic accents: Labour's surprise election result in 2017 changed all of that. Or so we thought. The team behind the British Election Study have now said that the largely reported "youthquake" (word of the year, don't you know) was a "myth". As we can see, in this fragment the increased emphasis and emotionality in the expression of irony about the election results is emphasized with the help of the so called parcellation (Or so we thought), in the expression of which the period is used. The keyword "youthquake" is quoted to emphasize its novelty and special status. Finally, an additional comment on this matter is introduced in parentheses, where with the help of a comma another ironic remark is added to those who might not have known this fact. Here the second keyword " $a$ myth" is also enclosed in quotation marks to accentuate the author's detachment from the given opinion, which obviously is the opposite. Thus, a whole spectrum of shades of meanings and thoughts is formed by means of 
punctuation, to explain the meaning of which in translation will require a fairly detailed presentation.

Another vivid example of a special function of punctuation in a media discourse can be the intentional absence of quotes in the citation of direct speech in the headline of "The Guardian" [13]: Russia is aiming to interfere in US midterm elections, warns CIA chief. The absence of quotes in this utterence emphasizes the fact that this statement can be seen as a piece of objective information rather than a private opinion of an individual, thereby strengthening the emotional impact on the reader, convincing the latter of the faithfulness of the author's opinion. In the subtitle of the article, the Director of the CIA's words, are marked with quotations to emphasize the authenticity of the information and point to its source: Mike Pompeo says 'I have every expectation that they will continue to try' to meddle in House and Senate races in November [Ibid]. And further in the article it is said: Mike Pompeo, director of the agency, told the $B B C$ he had not seen a "significant decrease" in Russian activity and his concerns extend to the House and Senate polls in November [Ibid]. In this sentence, the phrase "significant decrease" is written in quotation marks to emphasize the verifiability of the opinion and, on the other hand, to point out its precedence, since the discussion of the "intervention company of the Russians" has repeatedly occurred in various sources.

Thus, the analysis of punctuation marks in the modern communicative space indicates the appearance of new functional potentials associated with its expressive, emphatic and ludic functions.

Together with the expressivity of punctuation the use of typographic play can considerably reinforce a message. As means of typographic play let us take such devices as the use of capital letters, colours, font, a special design of lines, space, pictures, cartoons, etc., and other visual effects that enhance the language play [7]. The repertoire of typographic and punctuation devices are often widely employed within discourses of mass media editions. Thus, as an example of a typographic play we can offer the text from "The Harper's Bazaar", entitled "Is Time's Up the Next Step in the Me Too Movement?" by Jennifer Wright [14]. Firstly, the expressivity of the title is underlined by the use of a question mark in an utterance, which does not presuppose an answer, this being a rhetorical question, i.e. technically, it is a very strong emotional statement. Besides, the name of the movement is not marked with quotations, which implies that it is a common cliché everybody is aquainted with. Immediately after the title there is a funny ironic picture of doggies, the implication

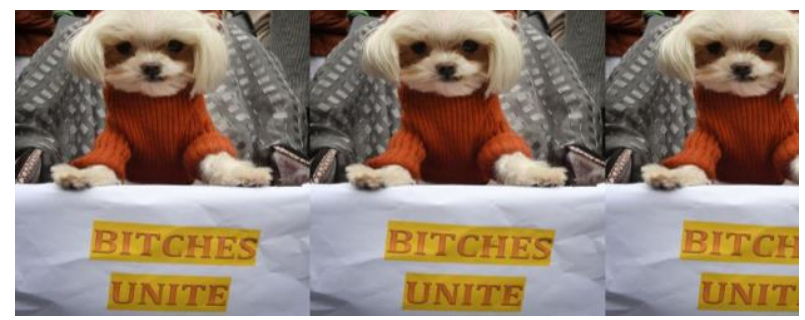

of this cartoon is that all creatures can fight for their trampled rights:

Further, in the text of the article we find various typographic devices to reinforce the message, such as: words in italics, bold formatting, parentheses, cf.:

"Sexual harassment isn't just a problem in the glamorous upper echelons of Hollywood and the Media and Capitol Hill. It's a problem at fast food restaurants, and hotels, and farms and just about every other underpaid industry across America. Make no mistake, it's a worse problem in those places. Minority women are more likely to experience sexual harassment than white women. Women in the lowest income bracket (with household incomes of less than \$7,500) are six times as likely to be sexually victimized as women in the highest income bracket (household incomes of over \$75,000.) Women without high school diplomas are 400 percent more likely to be assaulted than those with a bachelor's degree."[Ibidem].

So typography is an obvious domain together with punctuation, for language play, expressivity and written communication in general.

\section{Conclusion}

As a result of undertaken analysis it can be assumed that the category of expressivity of media discourse is related to a great extend (besides the verbal component of the message) to the usage of non-alphabetic signs, such as punctuation, graphics, typographic means (font, color, space, pictures, photoes, etc.). The major role in the function of text expressivity is played by punctuation, which constitute the sphere of syngraphemics, operating with the functions of emphasis, emotional coloring, or producing playing effect in discourses of modern media.

\section{Reference}

1. L. Truss, Eats, shoots \& leaves. The zero tolerance approach to punctuation (Fourth Estate, London, 2007)

2. V. G. Scherba, Theory of Russian Writing (Nauka, L, 1983)

3. T. McCormack, The fiction editor, the novel, and the novelist (Sidgwick\&Jackson, 1989)

4. M.V Divakova, Punctuation principles and syntactic norms of the Russian language of the first decades of the XX century (works of Russian writers and poets of $X X$ c. (M, 2005)

5. D. Crystal, The Cambridge encyclopedia of language (Cambridge University Press, NY, 1997)

6. M. Ryabova, Lambert Academic Publishing, LAP, 42 59 (2011)

7. D. Crystal, Language play (Penguin Books, 1998)

8. Yu.V. Popova, Phenomen of language play in an advertising discourse (English, German and Russian texts) (Rostov-na-Donu, 2014) 
9. V.Z. Sannikov, The Russian language through the mirror of language play (Languages of Russian Culture, M, 1999)

10. K.A. Balysheva, Philological Sciences. Questions of theory and practice. Literacy 6(1), 54-58, (2017)

11. Nikesh Shukla. Brit(ish) review - what does it mean to be black and British now? The Guardian, URL: https://

www.theguardian.com/books/2018/jan/29/britishby-afua-hirsch-review-identity-race-nikesh-shukla (date of access: 29.01.2018).

12. LiamYoung. Ignore the naysayers: the 2017 election youthquake wasn't a myth, The Guardian, URL: https:// www.theguardian.com/commentisfree/2018/jan/2 9/naysayers-2017-election-youthquake-wasntmyth-labour-surge (date of access: 29.01.2018).

13. David Smith. Russia is aiming to interfere in US midterm elections, warns CIA chief, The Guardian, URL:https: // www.theguardian.com/usnews/2018/jan/29/russia-is-aiming-to-interfere-inus-midterm-elections-warns-cia-chief (date of access: 30.01.2018).

14. Jennifer Wright. Is Time's Up the Next Step in th Me Too Movement? The Harper"s Bazaar, URL: https://www.harpersbazaar.com/culture/politics/ a14754192/metoo-2018-ending-sexual-assault/ (date of access: 2.03.2018). 